or semi-erect, but as far as I could observe nearly all the teeth came into play. When on fishing excursions in the lagoon, the sharks which constantly carried off the bait, were often caught, and in order to extract the hook, a large log, constantly carried in the boats for this purpose, was threateningly presented to its face, and "of "course instantly seized and beld on to for as lone as it took to perform the operation of extraction. If, when the fish is quite recently dead, pressure be made on the angle of the jaw, it is easy to observe the action of the rows of teeth.

Kesala, Bantam, Java, July

HENRY O. FORBES

\section{A Lunar Rainbow}

LAsT evening, September 3, at 10.40, a lunar rainbow was visible at Llanfairfechan, in a north-west direction. The arc was continuous, and of a brilliant white light. It appeared to stretch across Anglesey from Beaumaris to Puffin Island. The bow did not last more than $2^{\prime}$ from the time it was first observed by us.

F. E. KITCHENER

Llanfairfechan, September 4

\section{A Habit of Cattle}

IN the colony of NataI the cattle have an extraordinary liking for bones. They will stand for hours with a bone in the mouth quietly munching, sucking, or perhaps more correctly speaking, levigating the bone with the tongue. I have not heard that cattle have the same habit in the other colonies of South Africa, but I have been told that cattle exhibit the same taste in some parts of South Australia.

In Natal there is, I believe, a scarcity of chalk and limestone in the geological formation. Will this fact account for the habit? Do the eattle lick bones in search of lime?

Can any of your readers account for this strange taste in cattle?

I may mention that horses and other herbivorous animals in Natal do not exhibit the same taste.

Delagoa Bay, July 20

\section{THE AUGUST PERSEIDS}

$\mathrm{T}$ HIS remarkable meteor shower recurring annually on August Io is looked for every year with increasing diligence. To Quetelet belongs the credit of having first (in 1835) ascertained the epoch of its maximum display, though the month of August had long been known as one in which there was an abundance of falling stars. As early as 1762 Muschenbroek, in his work on "Natural Philosophy," stated that, according to his own observations, there were more shooting stars in August than at any other period of the year, and his remark is perfectly true applied to the first half of that month, though it is questionable whether the last half of August will bear comparison with that of July, when meteors fall very plentifully, and constitute a periodical display of special note on the 27th-3Ist. Since Quetelet determined the date of the Perseids, they have been expected every year with great interest, and from the time that Heis first began systematically to register the paths of meteors (nearly half a century ago) to the present day, observers have continued to record the successive apparitions of this prominent star-shower, so that multitudes of its meteors are now accumulated in the catalogues of British and foreign astronomers.

These Perseids appear to have belonged to our system at a very remote epoch, and to have been observed in considerable intensity as far back as the ninth century of our era. They form a continuous ring or zone of particles. The stream may vary in richness, that is to say, the particles may be very unequally distributed along the orbit, but it seems unbroken and manifests itself every year with more or less intensity from its accustomed point yielding many bright meteors of great swiftness, and almost invariably accompanied by phosphorescent streaks. It was from careful observations of the Perseids that Schiaparelli, in I866, was led to his theory of the connec- tion or identity of comets and meteors, and the first orbital coincidence found was that of the Perseids with Comet III. 1862, which seems to have been merely the nucleus or condensation of the particles forming this remarkable rneteor system.

The annual returns of this shower as observed and described by various observers, when compared together, show that in certain years the display is exceptionally brilliant ; in others it is far less imposing. Eduard Heis, at Muinster, counted I55 meteors per hour on August Io, 1863 , yet on the same night in 1867 the figures had fallen to 24 per hour. He gives the following as the horary numbers derived from observations between rob. and I2h. at several stations in Germany on August ro in different years :-

\begin{tabular}{|c|c|c|c|c|c|}
\hline Year. & Station. & $\begin{array}{c}\text { Hourly } \\
\text { number. }\end{array}$ & Year. & Station. & $\begin{array}{l}\text { Hourly } \\
\text { number }\end{array}$ \\
\hline $184 \mathrm{I}$ & 1achen & . 47 & 1863 & Münster & \\
\hline 0 & Aachen ... & $\ldots 60$ & 1863 & Gaesdonck & $\ldots 215$ \\
\hline 1847 & Aachen ... & ... 55 & 1863 & Peckeloh & $\ldots \operatorname{rog}$ \\
\hline 850 & Aachen ... & ... 37 & 1864 & Gaesdonck & $\ldots$ 10 \\
\hline 85 & Münster ... & $\ldots 89$ & 1864 & Ro & \\
\hline 35 & 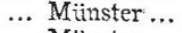 & ‥ $5^{6}$ & 1867 & stet & $\ldots$ \\
\hline 85 & M & ... 88 & 1867 & Peckeloh & \\
\hline $36 r$ & & $\ldots \quad 78$ & $1867 \ldots$ & urg & \\
\hline 86 & nck & ... 102 & $187 \mathrm{r}$ & Peckeloh & \\
\hline & $\mathrm{Pe}$ & ... 102 & 1872 & Rom & $\ldots$ \\
\hline 86 & om & $\ldots \quad 89$ & 1874 & Rom & $\ldots \mathrm{Ir}$ \\
\hline
\end{tabular}

Maximum in 1863 , minimum in 1867 and 1850 . There were also many Perseids in 1839 , when Heis counted 160 per hour. The displays of 1863 and $187 \mathrm{I}$ were of considerable intensity. On August Io, 1863, 9h. to $13 \frac{1}{4}$ h., Heis, assisted by several other observers at Münster, registered the paths of 602 shooting stars, and at Gaesdonck on the same night, 563 were recorded between 9 h. $17 \mathrm{~m}$. and I $2 \mathrm{~h} .9 \mathrm{~m}$. It may be mentioned as a curious anomaly, showing how much "personal equation" may have to do with the estimation of meteor magnitudes, that at the two stations referred to, the meteors were classified as follows :-

\begin{tabular}{lrrrrrrrrrr} 
& \multicolumn{3}{c}{ 1st mag. } & 2nd mag. & $3-6$ mag. & $\begin{array}{c}\text { Number } \\
\text { with } \\
\text { streaks. }\end{array}$ & $\begin{array}{c}\text { Total. } \\
\text { meteors. }\end{array}$ \\
Münster & $\ldots$ & 224 & $\ldots$ & 226 & $\ldots$ & 151 & $\ldots$ & 300 & $\ldots$ & 601 \\
Graesdonck & $\ldots$ & 37 & $\ldots$ & 84 & $\ldots$ & 442 & $\ldots$ & 158 & $\ldots$ & 563
\end{tabular}

The Münster observers evidently overrated the magnitudes to an enormous degree.

The display of $187 \mathrm{r}$, though less decided than in 1863 , was still a very rich return of these meteors. On August Io in that year, Signor Bassani, at Cosenza, in Italy, assisted by Signor Scrivani, counted 674 meteors from gh. to I6h., and at Boston, Mass., Messrs. Sawyer and Stephens, watching the sky from Ioh. to $15 \mathrm{~h}$. on the same night, recorded 567 meteors. Since that year the displays have not been of special brilliancy, though on August 10, 1874, 28r meteors were counted at Bristol by the writer in a watch of four hours, from 10.45 , to 14.45 , and on August 10, 1877, 354 meteors were seen in the five hours, from 9.30 to 14.30 , giving an hourly number (for one observer) in both years of about seventy.

Dr. Phipson suggested ${ }^{1}$ it was to be inferred from the observations that a maximum occurred at intervals of eight years. There had been considerable showers in 1839,1847 , and I863, and he pointed out that a similar manifestation was due in $187 \mathrm{r}$. In that year we had, as already described, an unusually numerous return of these meteors, and if the suspected periodicity held good, there would be another rich shower in 1879 . Perhaps on that account the Perseids of the present year were anticipated with a little more than ordinary interest, but the night of August Io was generally overcast in England (though at several stations a few meteors were discerned through breaks in the clouds), and thus the chief display has escaped us, though we may yet receive favourable reports

\footnotetext{
${ }^{1}$ See his "Meteors, Aerolites, and Falling Stars," p. 159.
} 
from foreign observatories. The nights of August 9 and Ir were partly clear, and a few observations were obtained. Mr. H. Corder, in Essex, saw 166 meteors on the IIth, between 9.30 and 15.30 , and found the radiant point very distinct at $45^{\circ}+57^{\circ}$. On August 4 a few meteors were seen from one of the earlier radiants at $33^{\circ}+51^{\circ}$, and on the 6 th from another at $36^{\circ}+58^{\circ}$. On the $9^{\text {th }}$ he watched from 9 h. $30 \mathrm{~m}$. until $\mathrm{r} 3 \mathrm{~h}$. seeing only 33 meteors (23 Perseids), but the moon was up and there were a few clouds. On the roth it was cloudy except between $12-12.30$, but a few meteors were seen later, in all 2I, I 8 being Perseids. The horary number cannot have been much over 30 . On the 12 th in $2 \mathrm{~h}$. he recorded 22 meteors (I4 Perseids). Two fine meteors were seen on the Ioth, the first, at 12.25, gave a vivid flash low down in Cetus, but only the streak was well seen. It was one of those instantaneous meteors often seen amongst the Perseids. Another was noted earlier (at 10.30) in Ursa $=$ Sirius, and leaving a fine streak.

At Welling, in Kent, 50 meteors were counted by two observers from IO.I 5 to II.I5.

At Debenham, Suffolk, on August 10, 12 meteors were seen between 10.30 and Ir.5, but the sky was much clouded. On the IIth, Io to II.30, 95 were recorded by one observer. These figures indicate a somewhat numerous return of the Perseids on August II. The radiant point was deduced as at $46 \frac{1}{4}+57 \frac{1}{2}$.

At Blackheath, S.E., Major Tupman found the normal radiant at $45^{\circ}+56^{\circ}$ on August II, and describes the Perseids as a poor display between IO. 15 and 12 .

At Bristol, on August 9, 33 meteors were seen by the writer between 9.30 and $I 2$, but there was much interference from clouds. On August I I 20 meteors were noted in the halfhour preceding IO.IO, and 15 of these were Perseids. Radiant point fairly well defined at $46^{\circ}+58^{\circ}$.

It will be seen that the four determinations of the radiant here given almost coincide at $45^{1} 2^{\circ}+57^{\circ}$, and prove the meteors to have exhibited an exact and distinctly marked centre of divergence this year. Mr. Greg's average position for the Perseids, derived from a large number of former observations, is at $44^{\circ}+56^{\circ}$, and the writer found, in 1874 , 1876 , and 1877 , a sharply defined radiant at $43^{\circ}+58^{\circ}$, but has more recently detected the existence of two other simultaneous showers from $\chi$ and $\gamma$ Persei.

Signor Denza reports (Gazetta Piemontese, August 27 and 28 ) that a total of I, 155 shooting stars were observed on the nights of August 9-I2 at seven Italian stations, chiefly at Volpeglino, by Signor Maggi and his assistants. The greatest number were recorded on August II. The Italian observers also succeeded in registering 295 meteors on twelve nights in July.

The apparent diffusion of the Perseid radiant point, often noticed by observers, is explained by the activity of many concomitant showers. Observations of the paths much foreshortened and close to the centres upon which they converge are the best to rely upon in getting accurate radiants. The vast number of simultaneous or contemporary systems in operation is shown by a discussion of a portion of the mass of observations which have been collected on the night of August ro. There are certainly more than 60 distinct meteor streams visible on that single night alone, and evidence of many others whose feebleness allows them to elude discovery. The extreme tenuity of some showers is such that no indication of their existence may be detected in a persistent watch of several hours' duration.

The true Perseids are characterised by the swiftness of their flights (the theoretical parabolic velocity being 38 miles per second) and by the bright and often enduring streaks left in their courses. They are sometimes very brilliant, ending in green flashes of remarkable lustre, and the luminous wands they leave behind guide the eye unerringly back to the point of space whence they are directed. They may be most favourably seen in the morning hours, when the radiant has attained considerable altitude; and the observer should take up a position commanding an uninterrupted view of the north-eastern constellations.

The limits of duration of this shower have not been definitely ascertained, but very few Perseids are visible before August 5 or after August 15. It is certain that they open as early as August 5, because Heis, in I864, saw a stationary meteor on that date, as brilliant as Venus, exactly in the radiant point at $44^{\circ}+57^{\circ}$. None of the real Perseids are visible as late as August 21,22 , or 23 , for of many shooting-stars seen on those dates this year, not one could be certainly attributed to that stream. It was formerly considered probable that the shower began at the end of July, but from the paths of hundreds of meteors recorded by the writer at Bristol during this epoch, there is little if any indication of the true Perseid radiant point. There is, however, a very rich display of swift streak-leaving meteors from a point below $\chi$ Persei, or more exactly at $32^{\circ}+53^{\circ}$, with which the old Perseids have been confounded, and given that shower an apparent duration far beyond the actual limits.

In addition to August ro there are other nights in that month when shooting-stars should be looked for and their horary numbers and radiants ascertained. Large meteors have been recorded in exceptional frequency on the Igth20 th and 22nd, and a series of three fine nights, occurring consecutively this year, on August 2I, 22, and 23, enabled the writer to obtain observations as follows:-

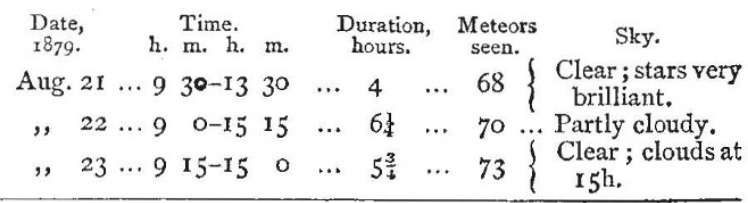

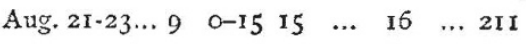

Not many large meteors were observed, but three of them were as bright as Jupiter. On the night of August 22 there was slight interruption from clouds, and the watch sustained for $6 \frac{1}{4}$ hours under such conditions was not equivalent to more than about 5 hours of clear sky. Of the 2 I I meteors seen, no less than 52 belonged to a splendidly well defined and rich shower of Draconids from a point at $291^{\circ}+60^{\circ}$, which thus apparently constitutes a special display at this epoch, and one of far more than ordinary importance. On August 2I, 2 I of its meteors were seen ; on August 22, II ; and on August 23, 20. They are slow-moving, bright meteors, sometimes trained, and almost invariably with short paths. The maximum occurred on August 21 , when in $\frac{3}{4}$ hour before IO.I 5,9 of the meteors were traced, though, singularly enough, during the next hour the radiant gave no visible sign. It is not a new system, for the same shower has been seen by many observers, and is No. 78 of $\mathrm{Mr}$. Greg's Catalogue of radiant points ( 1876 ), in which the centre is given at $282+60$ ( 12 obs.), and the duration from June 28 to August 25 (?). Major Tupman detected it in $187 \mathrm{I}$, on August $20-25$, at $280^{\circ}+58^{\circ}$, and Corder, in I 877 , saw I I meteors from $307^{\circ}+65^{\circ}$, on August I7, which may have been another manifestation of the same stream. In future years these Draconids should be anticipated as a rich and interesting periodical display. Though none of the true Perseids were visible on August $2 x-23$ this year, there was a moderately strong shower near $\alpha$ Persei, at $46^{\circ}+47^{\circ}$, giving bright, swift meteors, with streaks, and other radiant points were indicated in Perseus at $61^{\circ}+50^{\circ}$ and $62^{\circ}+35^{\circ}$, but no shower derived from the 2 I I meteors seen on August 2 I-23, would bear any comparison to that of the Draconids referred to.

The night of August 24 was overcast, but on August 25, before midnight, I 4 meteors were seen through openings in the storm-clouds. There were four Draconids, two of 
which were brilliant. One was observed in the twilight and mocnlight at 8.30 falling vertically in Delphinus, and the other, at 9.57 , was as bright as Venus, and gave a succession of three outbursts. Path from $79^{\circ}+76^{\circ}$ to $89^{\circ}+67^{\circ}$. There was a vivid flash at the end point which many persons who did not see the meteor itself mistook for lightning.

W. F. DENNING

\section{OUR ASTRONOMICAL COLUMN}

BIELA'S COMET.--In the actual uncertainty with regard to the present condition of Biela's comet, the importance of an exhaustive survey of the eastern sky during the dark mornings, i.e., the moonless mornings, of September and October, can hardly be exaggerated. The comet may possibly have been so disintegrated by this time that nothing further will be seen of it as such, but there must remain very great doubt as to such being the case. According to M. Otto Struve's observations of the two heads in $\mathrm{I}_{5}$, their diameters were still considerable, that of A being upwards of 20,000 miles, and of B 37,000 miles, and the brightness of the latter was equal to that of a star of Argelander's ninth magnitude.

With respect to the most promising plan of search, not much, perhaps, can be said, but if a number of observers are available, as it is to be hoped there may be, sweeps in zones of declination between pretty wide limits of right ascension, appear likely to insure some justifiable conclusion as to the comet's present state or position. Prof. Winnecke, we believe, is in possession of a 6 -inch refractor, mounted as "an "Airy's orbit-sweeper," and if the comet, or what remains of it, be still moving in the old orbit, this instrument, in such hands, will be of the utmost value in the examination of the proper sweeping-lines for the particular dates. But if the orbit has been sensibly changed by further perturbation, the effect "of which is wholly unknown to us, the necessary survey of the heavens will be, of course, only partially effected by this means, so that our only resource appears to be, as we have suggested, in a well-organised scrutiny of that portion of the sky wherein it is possible the comet might be situated, and there is yet time to provide for this, if arrangements have not been already made at those observatories which are occupied with cometary observations. To indicate the portion of the heavens in question, we subjoin the comet's places for the dates of new moon in September and October, according to different assumptions as to its distance from the perihelion, with similar places for five days subsequently:-

\begin{tabular}{|c|c|c|c|}
\hline \multicolumn{3}{|c|}{ September 15.5} & September $20^{\prime} 5$ \\
\hline & R.A. & Dist. & Decl. \\
\hline & $144: 3 \ldots$ & & $146^{\circ} \cdot 8 \ldots+8^{\circ} 3$ \\
\hline- xo & & & $140^{\circ} 0 \ldots$ \\
\hline & 16 & & $3^{2} 7 \ldots$ \\
\hline & 20 & & $45 \ldots$ \\
\hline 0 & $112.8 \ldots$ & & $15^{\circ}$. \\
\hline & $\mathrm{xO} 2 \cdot 2 \ldots+28$ & & $03.8 \ldots+$ \\
\hline \multicolumn{3}{|c|}{ October 15.5} & October $20^{\circ} 5$ \\
\hline & I 7 & & 172.9 \\
\hline & & & $167.5 \ldots-1 \cdot 8$ \\
\hline & +2 & & $1617 \ldots+12$ \\
\hline-10 & I & & I $55^{\circ} 3 \cdots \cdots$ \\
\hline $\begin{array}{l}-20 \\
-20\end{array}$ & $\begin{array}{r}10 \% 7 \\
+16.5\end{array}$ & & $\begin{array}{r}\mathbf{1} 48^{\circ} \text { I } \ldots .9+9.5 \\
139^{\circ} 0 \ldots+15.8\end{array}$ \\
\hline & & & \\
\hline
\end{tabular}

THE CluSter ABOUT $x$ CRUCIS.-In a communication to the Paris Academy of Sciences on August 25, M. Cruls, Director of the Observatory at Rio Janeiro, states that on comparing the present appearance of the stellar cluster about $k$ Crucis, with the map and observations made by Sir John Herschel, he finds notable changesconfirmed by detailed micrometrical measures which he intends to publish. Three double stars are found to be certainly in orbital motion, and there is a rectilinear dis- placement of the star near the red one. M. Cruls also mentions that he has registered a star $6.5 \mathrm{~m}$, which he believes has not been previously remarked, and which he suggests may be variable; it follows B.A.C. $4308=$ Lacaille 5293 by $\mathrm{rm} .4^{\prime} 26 \mathrm{~s}$, and is south of it, $4^{\prime} 14^{\prime \prime} \cdot 6$; according to Mr. Stone's position of this star for $1875^{\circ} \mathrm{O}$, the place of M. Cruls' object for the same year is in R.A. I2h. $44 \mathrm{~m}$. $5^{8} \cdot 52 \mathrm{~s}$., N.P.D. $149^{\circ} 43^{\prime} \mathrm{II}^{\prime \prime} \cdot \mathrm{O}$. We notice that the differences given by him are almost precisely the same as the differences between Lacaille 5288 and 5293 , though that in declination appears to be in the wrong: direction; thus, Mr. Stone's catalogue of I875 makes the position of 5293 with reference to 5288 , in R.A. + Im. 4.725., in Decl. + $4^{\prime} \mathrm{IO}^{\prime \prime} \cdot 4$. Is it possible that there can be any confusion here? Mr. Stone has not observed a star in M. Cruls' place.

This cluster is h. 3435, and Sir John Herschel's. micrometrical details relative to I Io of its components, will be found at p. I7 of his Cape volume; it is remarkable for the various colours of the stars, an attempt to illustrate which is made in the last edition of Chambers's "Descriptive Astronomy."

\section{GEOGRAPHICAL NOTES}

THE news of the arrival of Prof. Nordenskjöld at Yokohama on the evening of September 2, will have been received with satisfaction by the whole civilised world. The long-looked for solution of the problem of the North-East Passage has thus been practically accomplished. After being imprisoned in the ice near the Tshuctshe settlement for 264 days, viz., from September 28 , I878, until July 18 last, the Vega was at last released, and passing the East Cape, Behring's Strait, on July 20, entered St. Lawrence Bay, which may be said to form part of the Pacific Ocean. Crossing to Port Clarence on the American coast, a short stay was made there, and then the Professor re-crossed to Komian, while all the time dredging operations were carefully made, the formation of the sea-bottom at this spot being particularly interesting on account of the meeting of currents from the Arctic and Pacific oceans. No doubt the Vega will bring home a rich collection of specimens. The voyage was then continued, and after touching at St. Lawrence Island, Prof. Nordenskjöld visited Behring's Island, off the east coast of Kamtchatka, where he received the first news from Europe through the resident agent of the Alaska Trading Company. It was here that the professor discovered the fossil remains of the gigantic marine animal Rhytina stelleri. ${ }^{1}$ On August ig he left the island and continued his journey towards Japan. On the $3 x$ st the ship encountered a severe gale, during which the maintop was struck by lightning, which also slightly injured several of the crew. Without further accident the Vega anchored at Yokohama at IO.30 P.M. on the 2nd inst., where she will remain for a fortnight. No deaths trok place on board since the vessel left Sweden last summer, and thus the high-minded liberality of Herr Dickson, of Gothenburg, who supplied the means for the spirited enterprise of Prof. Nordenskjöld, is by the complete success of the latter deservedly rewarded.

In the August number of Petermann's Mittheilungen the narrative of journeys and voyages to Siberia is continued, with a map showing the most recent voyages through the Kara Sea. A special map has also been issued in which a portion of the course of Nordenskjöld in the Vega is laid down. The new coast-line of NorthEast Siberia is also laid down from the data supplied

I This animal was a species of Sirenia, and was exterminated by man with in a comparatively recent period. It was discovered about the middle of last century upon the island in question, which has its name from the celebrated traveller who was wrecked there in November, I74I, and who found the place inhabited by large numbers of these enormous animals. They were first described by Herr Steller, who was one of Behring's party. The discovery, hawever, seems to
seen later than the year 1768 . 